dons. The lateral production of the roots is a natural and general consequente of the presence of an hypoblast, which prevents the radicle from growing in a straight direction. In conformity to this reasoning, $\mathrm{Mr}$. $\mathbf{K}$. has classed the nelumbo among the monocotyledons. The discussion has then turned on the nature of these hypoblasts. Mr. de Mirbel compares what Mr. Richard thus names in the grasses, and which is the scucellum of Gaertner, with the cotyledon of the asparagi of the cannse and some other plants which have but one of them, and he concludes from this comparison, that the hypoblast of the grasses is precisely their cotyledon; which would place on his side all the analogies cited by Mr. Richard. Mr. Poiteau has abo written a memoir on this question, in which he coincides with de Mirbel.

Mr. Richard replies, that there is a greater difference than Mr. Mirbel thinks ; that the plumule of asparagus anci the other plants mentioned is enveloped in the cotyledon ; that it pesses through it, in order to get out; that it is a character essential to all the monocotyledon plants; that in the grasses, on the contrary, the plumule is enveloped in a tunic, in the form of a cone, distinct from the hypoblast, and that this tunic, envoloping the plumule, ought to be considered as the real cotyledon.

\title{
CASE IN WHICH THE OIL OF TURPENTINE WAS EMPLOYED WTTH SUCCESS IN TENIA.
}

COMMUNICATED BY DR. JOHN H. BROWN.

B. C. consulted me on account of his son, who had been afflicted with Tænia for six years, and had for that time occasionally discharged more or less of it. He was a lad of sixteen years of age, but considerably under the usual size. His general health appeared not to be materially affected by the disease. I recommended the $\mathrm{Ol}$. Terebinth Rect. and gave him directions to take fasting 31 ss. at 7 o'clock, and $\xi 1$ at 9 o'clock the 
next morning undiluted. At half after 9 o'clock the next morning I visited him. He told me he had taken the medicine agreeably to directions; that he retained the first dose an hour and 2 balf, when he vomited and threw off a smiall part of the oil ; had a discharge per anum, which brought away a few pieces of the worm ; and that the second dose had kept down, but had produced no evacuation. I waited until half past ten o'clock, and gave him another ounce of the OI. Terebinth. Rect. but he vomited immediately, and threw off a considerable part of it. Ileft him with directions to take a third at half after 11 o'cluck, A. M. The next morning I visited him again, when he presented me with upwards of twenty feet of the Txenia lata; one end of which I found upon examination terminated in the head. This was discharged between twelve and one o'clock the preced. ing day. He did not take the last ounce of the OI.Terebinth. Rect. at the timo prescribed, as he was apprehensive that he should not be able to retain it upon his stomach; but took it at three o'clock P. M. This operated powerfully, but did not bring away any more of the worm. This lad took the Ol. Terebinth. Rect. undiluted, with the same ease that he would rum or gin. He complained of its being a little warm in his stomach, of a littlc dizziness in his head; and his pulse was rather more frequent and hard than usual. He however was so little incommoded by it, that he sat up all day, and was out of the house a very considerable part of it.

From the above experiment, and from the information obtained from others, I am convinced that the Ol. Terebinth. Rect. may be given, in doses from $\xi_{i j}$ to $\xi_{i i j}$ with perfect safety. If however I had occasion to administer it again, I should prefer giving it by the $3 \mathrm{ss}$, and at short intervals ; as it would create less nausea, and the patient would be more likely to retain it. 